\title{
Frozen Stresses in Shape Memory Polymer Composites
}

\author{
GIOVANNI MATTEO TEDDE*, LOREDANA SANTO, DENISE BELLISARIO, LEANDRO IORIO, FABRIZIO QUADRINI \\ University of Rome Tor Vergata, Department of industrial Engineering, Via del Politecnico 1, 00133 Rome, Italy
}

\begin{abstract}
Shape Memory Polymer Composites(SMPCs) are a class of smartmaterials in which the structural properties of long-fiber polymer-matrix composites and the functional behavior of Shape Memory Polymers (SMP) are combined together. In this study, the frozen stresses resulting from fixing a deformed shape have been investigated. Two different samples were manufactured, with and without significant shape memory properties, and a three point flexural test equipment was used in order to fix a deformed shape. The forces and the resulting stresses were measured during the samples deformation and after the shape freezing. The experimental tests have shown that the shape memory sample has a better ability to fix a deformed shape, since its frozen stress is higher in all the tests.
\end{abstract}

Keywords: shape memory polymer composites, frozen stresses

SMPs are a class of polymeric smart materials that can be fixed in a temporary deformed shape, through the application of an external stimulus, and then can recover their original shape. For thermosetting SMPs, the temporary shape can be fixed by applying a limited load after heating the material above its glass transition temperature $(T)$ and cooling it under constraints. The recover occurs if the material is heated again above the $\mathrm{T}_{g}$ without any constraint [1].

SMPs have some important advantageous features in terms of density, processability, attainable strain and costs. However, they present modestmechanical properties and the force exerted during recovery is low. For this reason, the development of Shape Memory Polymer Composites (SMPCS) has attracted the researcher's interest as they combine the structural properties of long-fiber polymermatrix composites with the said functional behavior of SMP [2-3].

SMPCs are very interesting for aerospace applications, in particular for the production of self-deployable structure and several prototypes have been manufactured: structures for solar sails [4-5], space antennas, solar panels $[3,6]$. Moreover, this material can be used for the manufacturing of grabbing system, to be used for space cleaning operations [7]. The mentioned prototypes were produced by laminating two carbon fiber reinforced prepregs with a shape memory epoxy resin as interlayer. The shape memory properties of such resin (3M Scotchkote TM 206 N) were already tested in several experimental tests carried out on earth [8] and on orbit [911]. Also the prepregs matrix was an epoxy resin, but it does not have remarkable shape memory properties. An important advantage of using epoxy resins for the prepreg matrix and shape memory interlayer is the optimal adhesion between the different layers achievable in this way. Several tests were carried out, demonstrating the ability of these materials to easily change their shape and recover their original shape without remarkable damages in the structure.

In this study, three different methods have been tested to characterize shape memory materials, by evaluating stresses that can be frozen in the material in its temporary deformed shape. Two different samples were manufactured, with and without the shape memory interlayer, and a three point flexural test equipment was used in order to fix a deformed shape. The forces and the resulting stresses were measured during the deformation and after the shape freezing.

\section{Experimental part}

\section{Materials and methods}

Commercially available materials were used for manufacturing the SMPC samples. The thermosetting carbon fiber reinforced (CFR) prepregs utilized were supplied by Carbon Dream, having a $2 \times 2$ twill configuration and a thickness of $0.33 \mathrm{~mm}$. The matrix of this prepreg is an epoxy resin with limited shape memory property. The SMP interlayer was an uncured epoxy resin (3M Scotchkote $206 \mathrm{~N}$ ), which was available in the form of green powder, and was a one-part, heat curable, thermosetting epoxy coating, its density is $1.44 \mathrm{~g} / \mathrm{cm}^{3}$.

\section{SMPC samples production}

The prepregs were cut into strips of $30 \times 100 \mathrm{~mm}^{2}$. For the manufacturing of the sample with 2 layers without interlayer (CFR), 2 strips were put in an aluminum mold (30x100 $\mathrm{mm}^{2}$ ) with $45^{\circ}-45^{\circ}$ orientation and undergone to a compression molding process under a load of $65 \mathrm{kPa}$ over an hot plate (temperature $\mathrm{T}=150^{\circ} \mathrm{C}$ ) for $20 \mathrm{~min}$. A release film strips were putbelow the lower and above the upper prepreg layer in order to avoid adhesion between the composite material and the mold. The same process and parameters were used for the production of the SMPC sample (SMPC), but adding the shape memory resin

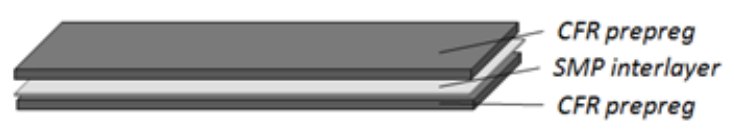

a

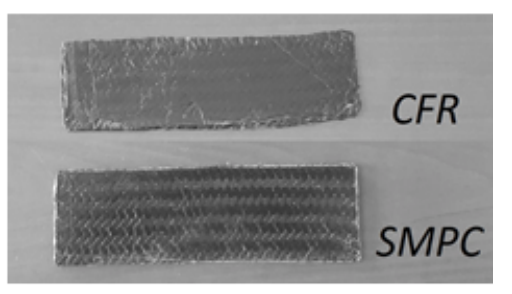

b
Fig. 1. Scheme of the SMPC sample (a) and the manufactured CFR and SMPC samples (b)

\footnotetext{
* email: tedde@ing.uniroma2.it
} 
between the 2 prepreg strips in order to obtain a $100 \mathrm{im}$ thick interlayer; $0.43 \mathrm{~g}$ of resin were uniformly distributed on the surface of the lower layer. As the CFR sample, the orientation of the prepreg fibers was $45^{\circ}-45^{\circ}$.

Figure 1 reports a scheme of SMPC sample and the manufactured SMPC and CFR samples.

\section{Flexural tests}

Flexural tests were carried out on all the samples in order to evaluate their ability to fix a deformed shape. An universal testing machine Alliance Insight 5 was used, with a 100 N MTS load cell; a three point bending equipment was mounted on the machine, with a support span of 80 $\mathrm{mm}$.

Three different tests were carried out as follows.

-Hot deformation: the sample was heated up to $T=120^{\circ} \mathrm{C}$ (heating time about $1 \mathrm{~min}$ ) and then deformed at a rate of $100 \mathrm{~mm} / \mathrm{min}$ up to a displacement of $10 \mathrm{~mm}$. A thermal gun was used for heating the sample; its temperature was monitored by using a thermocouple fixed on it. After the deformation, the crosshead was stopped and the thermal gun turned off, the force exhibited by the sample was measured during the hot deformation and for the following 10 min during its cooling;

-Cold deformation and heating by gun: the sample was deformed at room temperature at a rate of $10 \mathrm{~mm} / \mathrm{min}$ up to a displacement of $10 \mathrm{~mm}$ and kept for 5 min with the constrain. Then it was heated by using the thermal gun until a constant value of the load was reached;

-Cold deformation and heating by halogen lamp: the test is similar to the second test but the heating source used was $500 \mathrm{~W}$ halogen lamp. Figure 2 reports the tests configuration.

After each test, the samples were simply heated without any constraint above the epoxy resin $\mathrm{T}_{\mathrm{g}}$ that is about 120 ${ }^{\circ} \mathrm{C}$, in order to obtain their original shape.
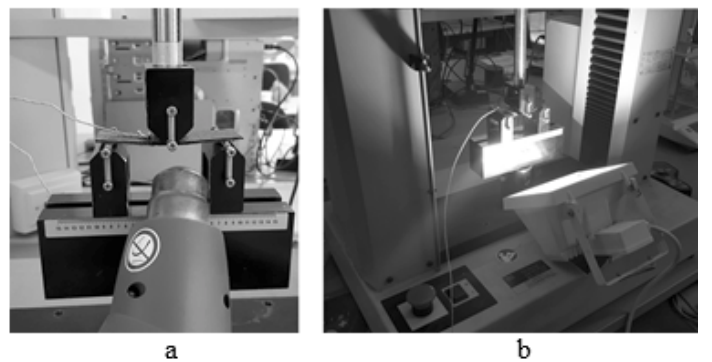

Fig. 2. Testl and Test 2 configuration (a) and Test 3 configuration (b)

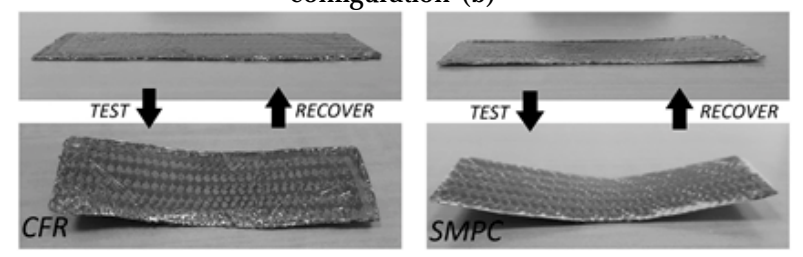

Fig. 3. CFR and SMPC samples deformation cycle

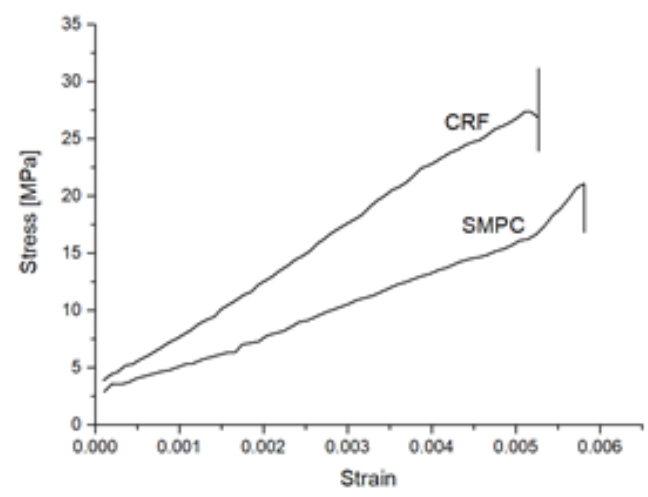

\section{Results and discussions}

\section{Samples dimensions}

The two produced samples had the same length and width (100 and $30 \mathrm{~mm}$ ) but different thickness, weight and density because of the shape memory interlayer in the SMPC sample. Such values are reported in table 1.

Table 1

SAMPLES FEATURES

\begin{tabular}{|l|c|c|c|}
\hline Sample & Thickness $[\mathrm{mm}]$ & Weight $[\mathrm{g}]$ & Density $\left[\mathrm{g} / \mathrm{cm}^{3}\right]$ \\
\hline CFR & 0.560 & 2.235 & 1.326 \\
\hline SMPC & 0.620 & 2.642 & 1.420 \\
\hline
\end{tabular}

Test 1. Figure 4 reports the expected curves from this test in the case of a perfectly elastic material and a perfectly shape memory material. During the cooling stage, the first material presents an increasing stress up to a constant value, higher than the one obtained at the end of the hot deformation, whereas the stress values in a perfect shape memory material tends to zero. Figure 5 reports the stressstrain and stress-time curves of Test 1 . After the deformation at $\mathrm{T}=120^{\circ} \mathrm{C}$, the CFR sample reached the higher maximum stress value of 27.4 MPa against 21.1 MPa reached by the SMPC sample, despite the greater SMPC strain. At the end of the deformation, when the crosshead was stopped and the heating source turned off, the load decreased for both the samples in a similar manner (reduction of 3.4 and 3.6 $\mathrm{MPa}$ for CFR and SMPC, respectively). During the cooling stage, the stress increased reaching a maximum value after about $100 \mathrm{~s}$. In this phase, the transition from rubbery to glassy state occurred. It is important to note that for the CFR sample this maximum was higher than the first maximum, reached after the deformation, whereas for the SMPC samples it was lower.

After the maximum value was reached, the material relaxed up to a constant value of the stress. A notable result is obtained on the SMPC sample, the stress value at the final plateau was lower than the peak after the hot deformation (- 19.7\%), whereas it was higher for the CFR sample $(+6.2 \%)$.

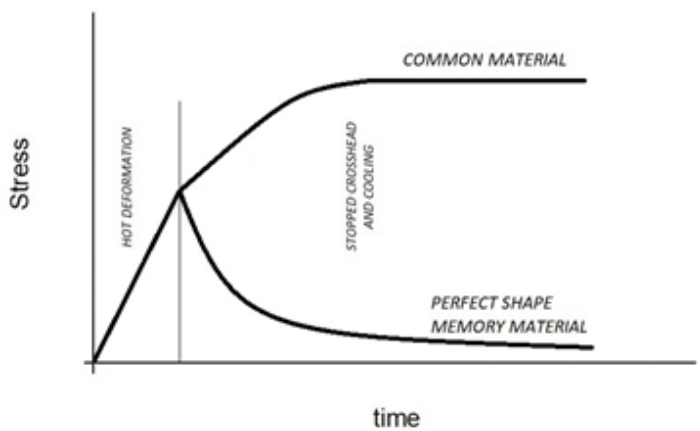

Fig. 4. Test 1 expected stress-time curves for a common material and a perfect shape memory material.

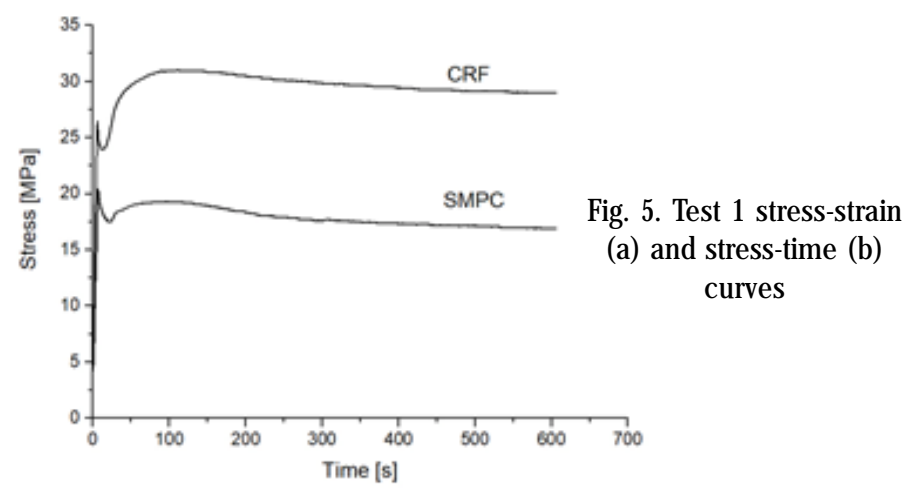

b 


\begin{tabular}{|l|c|c|}
\hline & CFR & SMPC \\
\hline 1) first peak (max stress 0-10 $\mathrm{s}[\mathrm{MP}]$ ) & 27.4 & 21.1 \\
\hline 2) trough (min stress 10-50 s [MPa]) & 23.9 & 17.5 \\
\hline 3) second peak (max stress 50-600 $\mathrm{s}$ [MPa]) & 31.2 & 19.4 \\
\hline 4) final plateau (average stress 500-600 s [MPa]) & 29.1 & 17.0 \\
\hline difference 1 - 2 [MPa] & -3.4 & -3.6 \\
\hline difference 1 - 3 [MP] & 3.8 & -1.8 \\
\hline difference 1 - 4 [MPa] & 1.7 & -4.2 \\
\hline difference 2 - 3 [MPa] & 7.2 & 1.9 \\
\hline difference 2 - 4 [MP] & 5.1 & -0.5 \\
\hline difference 3 - 4 [MPa] & -2.1 & -2.4 \\
\hline difference 1 - 2 [\%] & $-12.5 \%$ & $-17.2 \%$ \\
\hline difference 1 - 3 [\%] & $13.9 \%$ & $-8.4 \%$ \\
\hline difference 1 - 4 [\%] & $6.2 \%$ & $-19.7 \%$ \\
\hline difference 2 - 3 [\%] & $23.2 \%$ & $9.7 \%$ \\
\hline difference 2 - 4 [\%] & $21.4 \%$ & $-2.9 \%$ \\
\hline difference 3 - 4 [\%] & $-6.8 \%$ & $-12.3 \%$ \\
\hline
\end{tabular}

Table 2

NOTABLE VALUES OF TEST 1 STRESS-TIME CURVES
Table 2 reports all the notable values of the stress-time curves obtained in the Test 1 and the differences between these values: the first stress peak after the displacement (1), the trough when the heating phase starts (2), the maximum value during cooling (3) and the average stress in the final plateau (4).

Test 2. Figure 6 reports the stress-strain and stress-time curves. After the deformation, the SMPC sample reached the higher maximum stress value of $98.6 \mathrm{MPa}$ against 91.8 $\mathrm{MPa}$ reached by the CRF sample.

However, this fact mainly depends on the different maximum strain reached by the two samples since they differed in thickness. During the cold deformation, it was important to keep the samples in the elastic field, so as not to damage them. The stress-strain curves are similar up to the maximum strain of the CRF sample. During the $5 \mathrm{~min}$ after the prescribed displacement was reached, the samples relaxed and a reduction of the stress occurred. After the heating source was turned on, the stress quickly decreased reaching a constant value after few seconds. The thermal gun was then switched off (in the stress-time curve there is a correspondent little trough) and the plateau continued during the samples cooling. A limited further reduction of the stress occurred in this step, more evident in the SMPC sample. The frozen stress can be evaluated by the difference between the plateau reached in the cold loading phase and the final plateau reached at the end of the cooling phase.

The higher the frozen stress, the higher the expected force that would be exerted by the sample in a following recovery phase. Its expected value would be zero for a perfectly elastic material whereas a perfectly shape memory material would be able to freeze the entire load. The frozen stress of the SMPC sample ( $79.5 \mathrm{MPa})$ is higher than the CRF sample one (58.1 MPa) and this fact confirms the better ability of the SMPC sample to fix its shape than CFR sample and to froze the stresses. Table 3 reports all the notable values of the stress-time curves obtained in the Test 2 and the differences between these values: the stress peak after the displacement (1), the stress after $5 \mathrm{~min}$ keeping the maximum displacementat room temperature (2), the average stress of the plateau reached during the heating phase (3) and the average stress in the final plateau (4).

Comparison between Test 1 and 2. Figure 7 reports all the Test 1 and Test 2 stress-time curves. A good correspondence was obtained between the final plateaus of the two tests for both the samples.

Both the tests give information about the ability of the material to fix a deformed shape but Test 2 gives more information on the stress that can be frozen in the material in the deformed shape.

Furthermore, during the deformation at fixed strain the SMPC and CFR samples have required a similar load at room temperature (fig. 6a), butathigh temperature a lower load for the SMPC sample was needed (fig. 5 a).

Test 3. The final test was carried out by heating the sample by means of a halogen lamp. The stress-strain curves (fig.8a) are similar to that obtained in the Test 2, since the first part of the test, until the crosshead was stopped, was the same. For what concerns the stress-time curves (fig. 8b), the heating phase is very low and a stabilization of the stress values did not occur during the scheduled test time; for this reason a quantitative analysis of the residual stresses is not possible. Nevertheless, a qualitative analysis shows that the stress has decreased more quickly in the SMPC sample that is a further confirmation of its better ability to fix a deformed shape than the CFR sample.

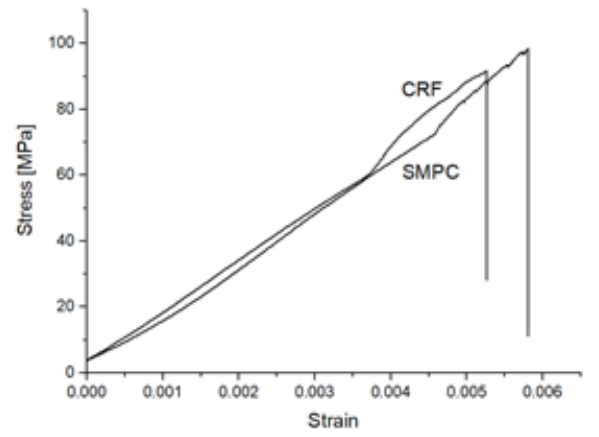

a

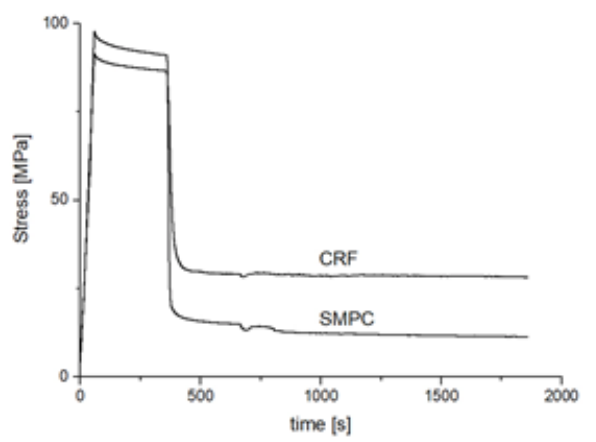

b
Fig. 6. Test 2 stress-strain (a) and stress-time (b) curves 
Table 3

NOTABLE VALUES OF TEST 1 STRESS-TIME CURVES

\begin{tabular}{|c|c|c|}
\hline 1) max stress [MPa] & CFR & SMPC \\
\hline 2) stress 6 min [MPa] & 91.8 & 98.6 \\
\hline 3) average stress 450-550 s [MPa] & 86.5 & 90.9 \\
\hline 4) average stress 1500-1860 s [MPa] & 28.7 & 15.7 \\
\hline difference 1 - 2 [MPa] & -5.3 & -71.4 \\
\hline difference 1 - 3 [MPa] & -62.2 & -82.9 \\
\hline difference 2 - 3 [MPa] & -56.8 & -75.2 \\
\hline difference 1 - 4 [MPa] & -63.4 & -87.2 \\
\hline difference 2 - 4 [MPaa] & -58.1 & -79.5 \\
\hline difference 3 - 4 [MPa] & -1.3 & -4.3 \\
\hline difference 1 - 2 [\%] & $-5.8 \%$ & $-7.8 \%$ \\
\hline difference 1 - 3 [\%] & $-67.7 \%$ & $-84.0 \%$ \\
\hline difference 2 - 3 [\%] & $-65.7 \%$ & $-82.7 \%$ \\
\hline difference 1 - 4 [\%] & $-69.1 \%$ & $-88.4 \%$ \\
\hline difference 2 - 4 [\%] & $-67.2 \%$ & $-87.4 \%$ \\
\hline difference 3 - 4 [\%] & $-4.4 \%$ & $-27.4 \%$ \\
\hline
\end{tabular}

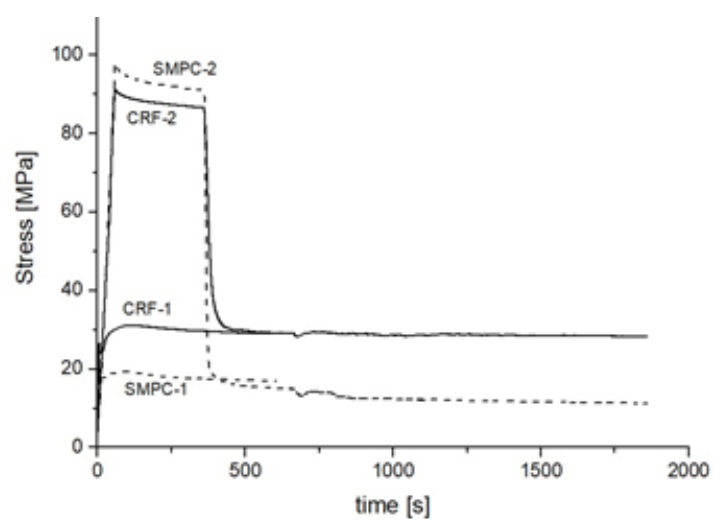

Fig. 7. Test 1 and Test 2 stress-time curves comparison

\section{Conclusions}

In this paper, SMPC materials have been compared with traditional Carbon Fiber Composite in order to evaluate their ability to fix a deformed shape maximizing the resulting frozen stress. Three different tests have been carried out and all this tests have shown that the frozen stresses after a deformed shape fixing are higher in the sample with a shape memory interlayer. The Test 2 appears the most convenient to measure such stresses.

Moreover, the use of a thermal gun for the heating phase was more efficient than the use of a halogen lamp. In fact, the stabilization of the stress was reached more quickly. The two tests carried out with the thermal gun have also demonstrated that the residual stress does not depend on the temperature of the fixing step.

\section{References}

1. LENDLEIN A., KELCH S., Angew. Chem. Int. Edn., 41, 2002, p. 2034; 2. LIU Y., DU H., LIU L., LENG J ., Smart. Mater. Struct., 23:023001, 2014; 3. SANTO L., QUADRINI F., Smart Polymer Nanocomposites, 2017, p. 303;

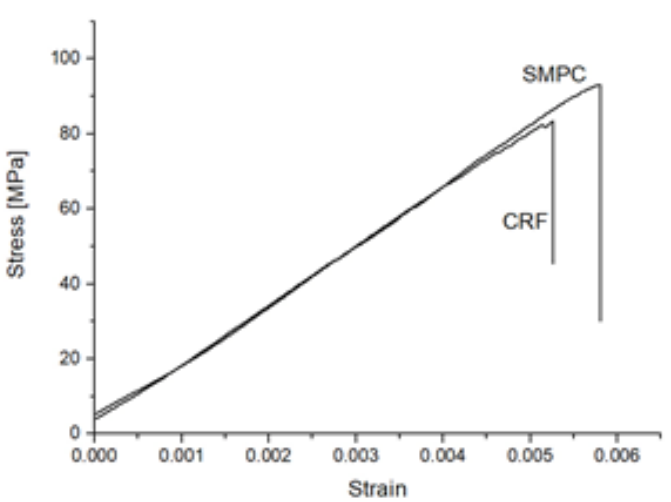

a

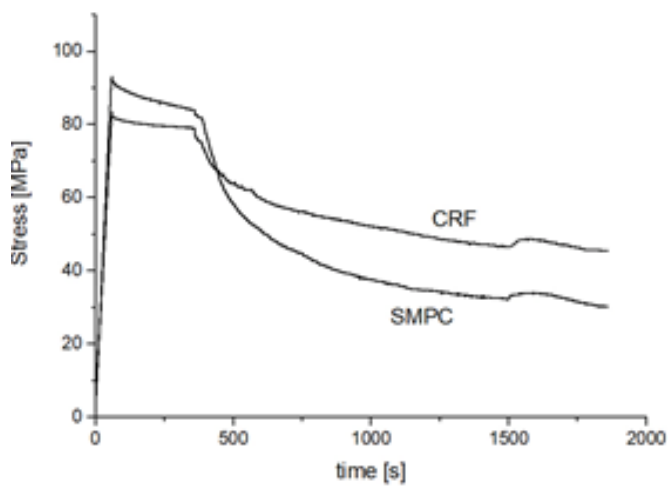

b

Fig. 8. Test 3 stress-strain (a) and tress-time (b) curves.

4.SANTO L., QUADRINI F., ACCETTURA A.G., VILLADEI W., Procedia Eng., 88(C), 2014, p. 42.

5. SANTO L., QUADRINI F., BELLISARIO D., ACCETTURA A.G., Proceedings of the 2016 Manufacturing Science and Engineering Conference MSEC2016, 2016, USA;

6. SANTO L., QUADRINI F., BELLISARIO D., IOP Conference Series: Materials Science and Engineering, 161, nr. 1, 2016, 012066; 7. QUADRINI F., TEDDE G.M., SANTO L., ASME 2015 International Manufacturing Science and Engineering Conference, Volume 1: Processing, 2015, USA;

8. SQUEO E.A., QUADRINI F., Smart. Mater. Struct., 19, 2010, p.105002;

9. QUADRINI F., SANTO L., SQUEO E.A., Mater. Lett., 69, 2012, p. 20;

10. SANTO L., QUADRINI F., SQUEO E.A., DOLCE F., MASCETTI G., BERTOLOTTO D., VILLADEI W., GANGA P-L., ZOLESI V., Microgravity Sci. Tec., 24, 2012, p. 287;

11. SANTO L., QUADRINI F., GANGA P.L., ZOLESI V., Aerosp. Sci. Technol., 40, 2015, p. 109.

Manuscript received: 15.09 .2018 